\title{
The effect of diabetic autonomic neuropathy on P-wave duration, dispersion and atrial fibrillation
}

Andrzej Bissinger, Tomasz Grycewicz, Wlodzimierz Grabowicz, Andrzej Lubinski

Department of Invasive Cardiology and Cardiodiabetology, Medical University, Lodz, Poland

Submitted: 18 August 2010

Accepted: 13 December 2010

Arch Med Sci 2011; 7, 5: 806-812

DOI: 10.5114 /aoms.2011.25555

Copyright (๑) 2011 Termedia \& Banach

\section{Abstract}

Introduction: Atrial fibrillation (AF) is the most common sustained arrhythmia. Diabetic autonomic neuropathy (DAN) is a frequent complication of diabetes mellitus and has a negative impact on the cardiovascular system. There are no data about the occurrence of paroxysmal atrial fibrillation (PAF) in the population with DAN.

Material and methods: We analysed the data of 100 patients with PAF. The study population was divided into three groups: group I: 28 patients with diabetes mellitus (DM) and DAN, group II: 34 patients with DM without DAN, and group III: 38 patients without DM. P-wave duration (FPD) and dispersion (PWD) were measured during sinus rhythm and AF episodes were counted during 12 months of follow-up.

Results: Recurrence of PAF was higher in group I (47 episodes/year) compared to groups II and III (26 and 22 episodes/year) $-p<0.01$. The FPD was longer in group I $(137.4 \pm 12.0 \mathrm{~ms}$ vs. $126 \pm 23.0 \mathrm{~ms}$ in II group and $129 \pm 18.3 \mathrm{~ms}$ in group III; $p<0.001)$. The PWD was longer in patients with DAN ( $53 \pm 19$ ms vs. $36 \pm 18$ ms and $34 \pm 20 \mathrm{~ms}, p<0.001$ ).

Conclusions: The results showed that the presence of DAN caused a significant increase in P-wave duration and dispersion, which might be responsible for the recurrence of $A F$

Key words: diabetes mellitus, autonomic nervous system, atrial fibrillation, electrophysiology.

\section{Introduction}

Atrial fibrillation (AF) is the most common sustained arrhythmia encountered in clinical practice and is responsible for a substantial portion of excess cardiovascular morbidity and mortality [1]. Its prevalence doubles with each advancing decade of age, from $0.5 \%$ at the age of $50-59$ years to almost $9 \%$ at the age of $80-89$ years. For men and women, respectively, diabetes conferred a 1.4- and 1.6-fold AF risk after adjusting for other associated conditions [2].

Diabetic autonomic neuropathy (DAN) has a significant negative impact on the cardiovascular system. Typical findings in DAN include cardiac arrhythmias, cardiovascular instability, exercise intolerance and also higher mortality among diabetic patients [3]. The DAN is a frequent complication in diabetes mellitus (DM) with a reported prevalence of $46 \%$ in DM diagnosed less than 5 years ago and up to $70 \%$ with $>20$ years of diabetes [4]. Diagnosis of DAN is, perhaps, one of the most overlooked of all serious
Corresponding author: Andrzej Bissinger MD, PhD Department of Invasive Cardiology and Cardiodiabetology Medical University 113 Zeromskiego 90-549 Lodz, Poland Fax: +48426393563 Phone: +48426393563 E-mail: abissinger@gmail.com 
complications of DM. There are no data about the occurrence of paroxysmal atrial fibrillation (PAF) in the population with DAN.

P-wave dispersion (PWD) is an electrocardiographic marker that has been associated with inhomogeneous and discontinuous propagation of sinus impulses [5, 6]. Prolonged P-wave dispersion is commonly found in patients with a history of PAF $[5,7]$, and PWD was a clinically useful predictor of progression from PAF to persistent AF [8].

The purpose of our study was to evaluate whether the presence of DAN increases inhomogeneous atrial conduction and recurrence of AF in patients with DM type 2 .

\section{Material and methods}

The population in the present study comprised patients with a history of PAF recurrences after successful electrical cardioversion for persistent atrial fibrillation. Cases with left ventricular systolic dysfunction defined as left ventricular ejection fraction $<50 \%$, with left atrial diameter $>4.5 \mathrm{~cm}$, after myocardial infarction, with hypo- or hyperthyroidism and receiving antiarrhythmic drugs except $\beta$-blockers were excluded. Of 108 eligible participants, 100 complied with the study, because they had successfully finished 12-month follow-up. Reasons for not completing the study were as follows: unsuccessful cardioversion after recurrence of AF $(n=3)$, stroke $(n=2)$, patient's refusal to continue the study $(n=2)$, re-location $(n=1)$.

Patients with DM history, taking oral antidiabetic medicine or insulin were accepted as diabetic. On entering the study, Ewing's tests, P-wave duration and dispersion measurements and echocardiographic parameters were assessed. The diagnosis of DAN was established on the basis of Ewing's tests [4, 9] set together in Table I. Autonomic function tests were performed in the morning after 12 -h fasting. The DAN was identified when $\geq 3$ of 5 tests were positive.

At the time of electrocardiographic recording all the subjects were in sinus rhythm. Simultaneously 12-lead ECG was recorded at the speed of $200 \mathrm{~mm} / \mathrm{s}$ in supine position. CardioLab v. 6.0 General Electric Medical Systems was used for ECG recordings and measurements. The measurements of P-wave duration and dispersion were performed manually by two of the investigators blinded to other patient information.

P-wave duration was measured from the onset to the offset of the P-wave in the lead with the longest $P$-wave. The onset and offset were defined as the junction between the P-wave pattern and the isoelectric line. P-wave dispersion was defined as the difference between the maximum and minimum P-wave duration in 12 leads. If the onset and termination of the P-wave could not be identified with certainty in a particular lead, the lead was excluded from the analysis. An ECG with measurable $P$ waves in $<8$ leads was also excluded from the analysis.

The study population was divided into three groups depending on the occurrence of DM and DAN. Group I consisted of 28 patients with DM and DAN (19 men, 9 women, aged $69 \pm 7.6$ years). Group II consisted of 34 patients with DM without DAN (22 men, 12 women, aged $68 \pm 6.8$ years) and group III consisted of 38 patients with PAF without DM ( 27 men, 11 women, aged $68 \pm 7.4$ years).

During 12-month follow-up the patients were scheduled for examinations once a month at the cardiology outpatient clinic. Twenty-four-hour Holter electrocardiogram (ECG) monitoring was also performed monthly. All patients were instructed and received written information how to visit the GP doctor and perform ECG recording in any case of heart palpitation. The ECG recordings were made

Table I. Ewing's tests and DAN diagnosis

\begin{tabular}{|c|c|c|}
\hline Test & Description & Positive if \\
\hline $\begin{array}{l}\text { Expiration/Inspiration } \\
(\text { E/I) ratio }\end{array}$ & $\begin{array}{l}\text { The patient was asked to take deep breaths for } \\
10 \text { min with frequency about } 6 \text { breaths/min }\end{array}$ & Max $H R-\min H R<10$ bpm \\
\hline Valsalva maneuver & $\begin{array}{l}\text { The patient was asked to blow into a mercury } \\
\text { sphygmomanometer and to maintain the pressure } \\
\text { at about } 40 \mathrm{mmHg} \text { for } 15 \mathrm{~s}\end{array}$ & $\operatorname{Max} R R / \min R R<1.2$ \\
\hline $\begin{array}{l}\text { Postural heart rate response: } \\
\text { maximum-minimum } \\
\text { (30:15 ratio) }\end{array}$ & $\begin{array}{l}\text { HR was measured in horizontal position and again } \\
2 \text { min later after standing upright }\end{array}$ & $30^{\text {th }} R R / 15^{\text {th }} R R<1.0$ \\
\hline $\begin{array}{l}\text { Postural blood pressure } \\
\text { response }\end{array}$ & $\begin{array}{l}\text { Blood pressure in the non-dominant arm was recorded } \\
\text { with a mercury sphygmomanometer first in horizontal } \\
\text { position and again in 1, } 3 \text { and } 5 \text { min after standing upright }\end{array}$ & $\begin{array}{l}\text { A fall of BP by } \\
>20 \mathrm{mmHg} \text { systolic } \\
\text { or }>10 \mathrm{mmHg} \text { diastolic }\end{array}$ \\
\hline Isometric hand grip test & The patient was asked to cramp dynamometer for $5 \mathrm{~min}$ & Diastolic BP rise $<10 \mathrm{mmHg}$ \\
\hline
\end{tabular}

$H R$ - heart rate (bpm), BP - blood pressure, RR - interval between successive R-waves on ECG (ms) 
in all instances when clinical evaluation suggested AF. Only ECG proven AF episodes longer than $10 \mathrm{~s}$, registered during normal or Holter ECG, were regarded as AF recurrence.

The study was approved by the Local Ethics Committee and all included subjects gave informed consent.

\section{Statistical analysis}

All numeric variables were expressed as mean \pm SD and categorical variables as percentages. Statistical analysis was performed using Student's t-test, or Mann-Whitney test in the case of nonnormal distribution of values (Shapiro-Wilk test). The groups were compared independently: group I and II, I and III, II and III. A $p$ value $<0.05$ was considered statistically significant.

\section{Results}

The clinical profiles of the study patients are presented in Table II. All groups were statistically comparable for demographic parameters, duration and control of diabetes, coexisting diseases and treatment. Echocardiographic parameters, particularly left ventricular ejection fraction and left atrial diameter, were also comparable in all patients.

During 12-month follow-up, AF episodes were recorded in 18 patients from group I, 12 from group II and 14 from group III. The frequency of PAF recurrence was significantly higher in patients with DAN (group I) (47 episodes/year) compared to groups II and III (26 and 22 episodes/year, respectively) ( $p<0.01)$. The PAF recurrence episodes were mainly detected by Holter monitoring and were asymptomatic in all groups. The numbers of asymptomatic episodes were 36 in group I, 21 in group II, and 18 in group III. Results of electrocardiographic measurements are presented in Table III.

P-wave duration was significantly longer in patients with DAN $(137.4 \pm 12.0$ ms vs. $126 \pm 23.0$ ms in DM without DAN and $129 \pm 18.3 \mathrm{~ms}$ in patients without DM; $p<0.001)$. Similarly, P-wave dispersion was longer in patients with DAN $(53 \pm 19$ ms vs.

Table II. Clinical profiles of the study patients

\begin{tabular}{|c|c|c|c|c|}
\hline Parameter & $\begin{array}{c}\text { Group I } \\
\text { DM DAN (+) } \\
(n=28)\end{array}$ & $\begin{array}{c}\text { Group II } \\
\text { DM DAN (-) } \\
(n=34)\end{array}$ & $\begin{array}{c}\text { Group III } \\
\text { DM (-) } \\
(n=38)\end{array}$ & Value of $p$ \\
\hline Gender (female/male) & 9/19 & $12 / 22$ & $11 / 27$ & ns \\
\hline Age [years] & $69 \pm 7.6$ & $68 \pm 6.8$ & $68 \pm 7.4$ & ns \\
\hline $\begin{array}{l}\text { Duration of persistent AF } \\
\text { before first cardioversion [days] }\end{array}$ & $73 \pm 86$ & $82 \pm 79$ & $69 \pm 83$ & ns \\
\hline Duration of diabetes [years] & $8.3 \pm 4.6$ & $7.1 \pm 3.8$ & - & ns \\
\hline $\mathrm{HbA}_{1 \mathrm{c}}[\%]$ & $8.4 \pm 2.1$ & $8.6 \pm 1.9$ & $5.6 \pm 2.3$ & $\begin{array}{l}\qquad p<0.001 \\
\text { group III vs. I and II }\end{array}$ \\
\hline Body mass index $(\mathrm{BMI})\left[\mathrm{kg} / \mathrm{m}^{2}\right]$ & $28.7 \pm 4.6$ & $29.2 \pm 6.0$ & $27.6 \pm 5.1$ & ns \\
\hline eGFR [ml/min] & $65 \pm 7$ & $67 \pm 9$ & $70 \pm 6$ & ns \\
\hline Previous diagnosed hypertension [\%] & 53 & 56 & 53 & ns \\
\hline Hyperlipidaemia [\%] & 43 & 44 & 43 & ns \\
\hline Left ventricular ejection fraction (EF) [\%] & $58 \pm 12$ & $54 \pm 17$ & $56 \pm 11$ & ns \\
\hline Left atrial diameter $[\mathrm{cm}]$ & $4.0 \pm 2.3$ & $3.8 \pm 3.2$ & $4.1 \pm 3.2$ & ns \\
\hline \multicolumn{5}{|l|}{ DM therapy [\%] } \\
\hline Insulin & 25 & 32 & - & \\
\hline $\begin{array}{l}\text { Oral anti-diabetic } \\
\text { (sulphonylureas and/or biguanides) }\end{array}$ & 75 & 68 & - & \\
\hline \multicolumn{5}{|l|}{ Concomitant medication [\%] } \\
\hline$\beta$-blocker & 68 & 67 & 70 & ns \\
\hline ACEI & 87 & 84 & 90 & ns \\
\hline Diuretics & 63 & 68 & 60 & ns \\
\hline Statins & 47 & 57 & 47 & ns \\
\hline
\end{tabular}

DM DAN (+) - diabetes mellitus with diabetic autonomic neuropathy, DM DAN (-) - diabetes mellitus without diabetic autonomic neuropathy, DM (-) - patients without diabetes mellitus, ACEI - angiotensin-converting enzyme inhibitors, hyperlipidaemia = total cholesterol $\geq 200 \mathrm{mg} / \mathrm{dl}$, hypertension = blood pressure $\geq 140 / 90 \mathrm{mmHg}$, eGRF-estimated creatinine clearance (Cockcroft-Gault formula) 
Table III. Results of electrocardiographic measurements

\begin{tabular}{|lcccc|}
\hline Parameter & DM DAN (+) & DM DAN $(-)$ & DM $(-)$ & Value of $p$ \\
\hline P-wave duration (FPD) [ms] & $137 \pm 12.0$ & $126 \pm 23.0$ & $129 \pm 18.3$ & $<0.001^{*}$ \\
\hline P-wave dispersion (PWD) [ms] & $53 \pm 19$ & $36 \pm 18$ & $34 \pm 20$ & $<0.001^{*}$ \\
\hline
\end{tabular}

DM DAN (+) - diabetes mellitus with diabetic autonomic neuropathy, DM DAN (-) - diabetes mellitus without diabetic autonomic neuropathy, DM (-) - patients without diabetes mellitus, ${ }^{*} p-D M D A N(+)$ vs. DM DAN (-) and DM (-)

$36 \pm 18 \mathrm{~ms}$ and $34 \pm 20 \mathrm{~ms}$, respectively; $p<0.001)$. Figures 1 and 2 present an example of P-wave dispersion and duration, respectively.

\section{Discussion}

In the current study, frequent recurrence of AF and significantly longer $\mathrm{P}$-wave duration and dispersion were demonstrated in patients with $D M$ and DAN compared with the remaining groups. This is the first study which shows an association between PAF and DAN. Our results suggest that autonomic neuropathy may be responsible for the recurrence of AF probably through its impact on intra- and interatrial conduction resulting in inhomogeneous propagation of sinus impulses. Most research has been focused on molecular and physiological mechanisms, but the autonomic nervous system has not been consistently viewed as a "critical point" in the clinical approach to patients with PAF. Coumel was the first to coin the terms vagal and adrenergic AF in his landmark clinical and experimental studies on autonomic tone and AF $[10,11]$. He reported that "vagal AF" usually occurs in young patients, more frequently men, who have no structural heart disease. It tends to occur postprandially and at night. But "adrenergic $A F$ " is usually triggered by physical or emotional stress and often occurs in the presence of heart disease.

Interestingly, when the role of heart rate variability (HRV) was assessed as a predictor of AF onset in the Framingham Heart Study, autonomic dysregulation at baseline as reflected by altered HRV was not associated with the risk of AF. These

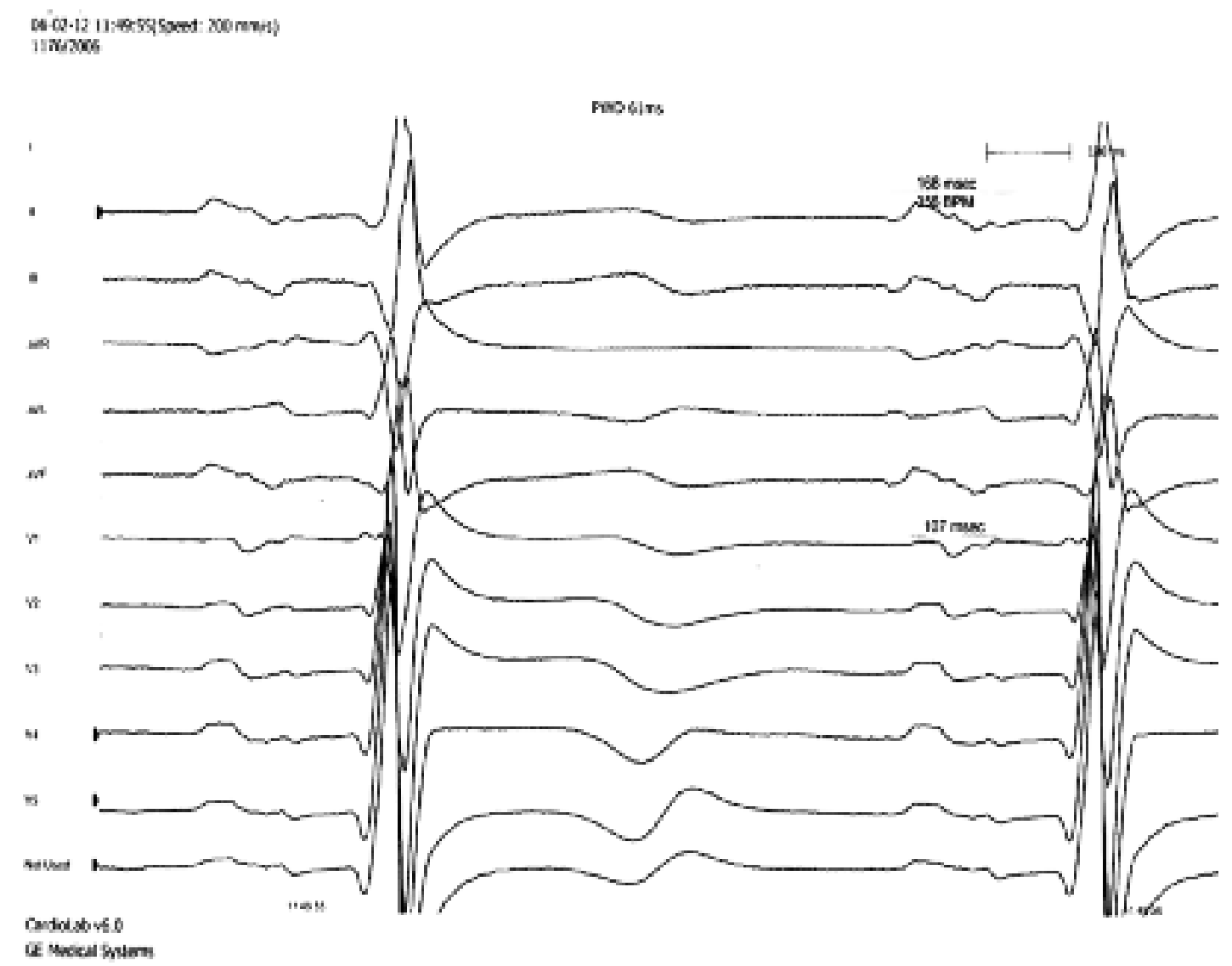

Figure 1. Example of P-wave dispersion (PWD) measurement. The longest P-wave is $168 \mathrm{~ms}$ in lead II, the shortest $\mathrm{P}$-wave is $107 \mathrm{~ms}$ in V1; PWD $=61 \mathrm{~ms}$ 


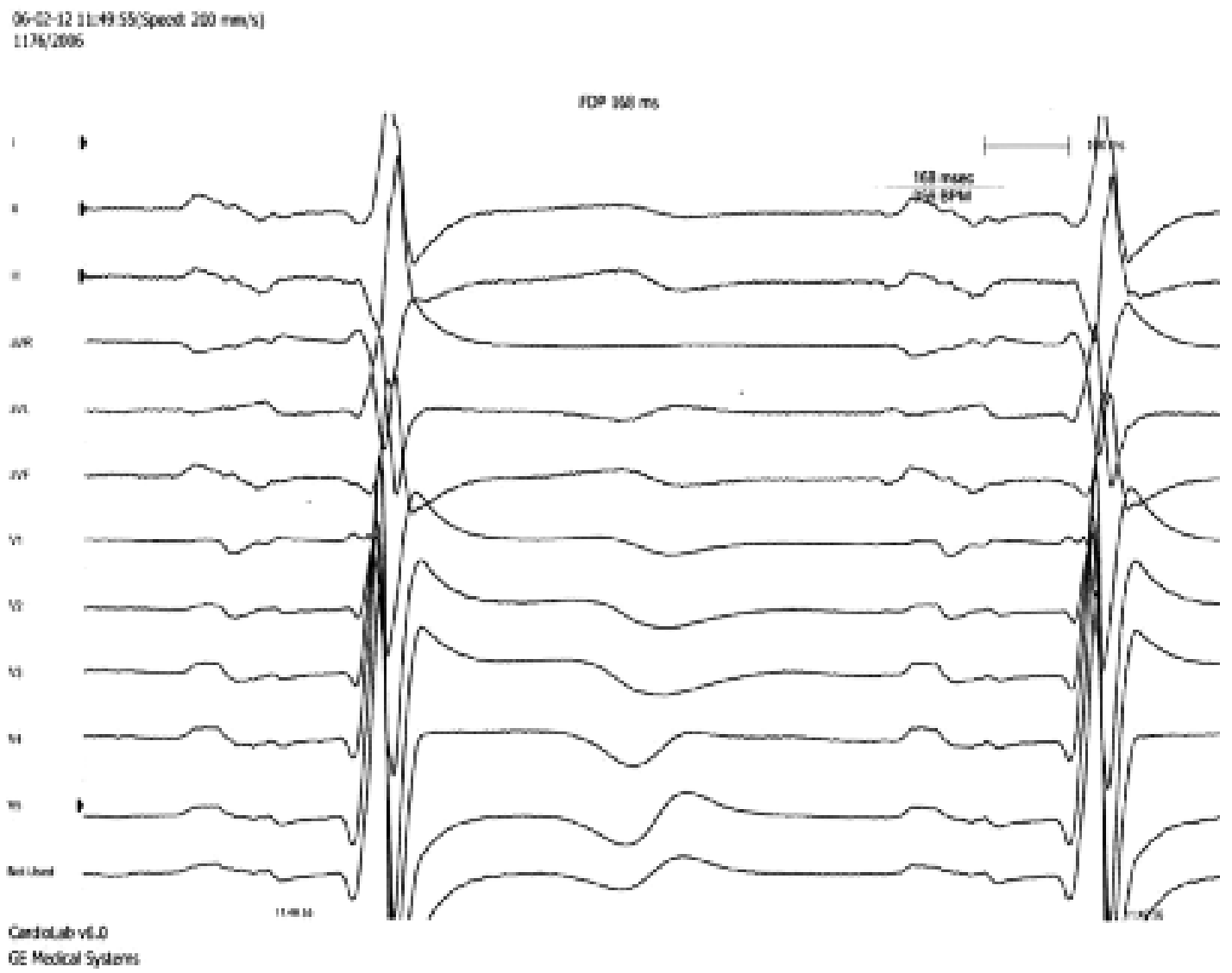

Figure 2. Example of P-wave duration measurement. The longest P-wave duration is $168 \mathrm{~ms}$ in lead II

seemingly conflicting results are perhaps explained by differences in the patient population, the time frame during which HRV was measured and by the intrinsic limitation of this technique. Therefore, in our study Ewing's tests, not HRV, were used to evaluate autonomic system dysfunction. These simple, non-invasive tests introduced in the early 1970s are still applied successfully by many investigators [3, 12].

Our study suggests that inhomogeneous atrial depolarization is the potential trigger of PAF in patients with DAN. We used P-wave duration and dispersion to estimate this phenomenon. There are a lot of studies confirming the role of $\mathrm{P}$-wave duration and dispersion as non-invasive markers associated with PAF $[5,6,13]$. P-wave duration longer than 110 ms suggests interatrial block, which is associated with development of atrial fibrillation [14].

P-wave duration and dispersion were reported to be influenced by the autonomic tone, which induces changes in the velocity of impulse propagation, but the results are not unequivocal. Chema et al. [15] showed that sympathetic stimulation with isoproterenol or epinephrine significantly shortened P-wave duration but $\beta$-adrenergic blockade prolonged it. Also there are limited data concerning the effect of administration of catecholamines or $\beta$-blockers on conduction velocity. Tukek et al. reported that after the Valsalva manoeuvre, maximum P-wave duration and PWD increased significantly [16]. Imamoglou et al. reported that PWD is increased in children with DM type 1 and values for the dispersion in the diabetic subjects were similar before and after the Valsalva manoeuvre, whereas dispersion was found to be significantly increased after this manoeuvre in the controls [17]. Also, Yazici et al. reported prolongation of PWD in DM patients; the authors of this publication did not analyse autonomic nervous function, but speculated that the possible mechanism of dispersion could be atrial myopathy and fibrosis [18].

Autonomic dysfunction in DM leading to DAN is caused by diffuse and widespread damage of sympathetic and parasympathetic nerves. Hypotheses concerning the multiple aetiologies of DAN include metabolic insult to nerve fibres, neurovascular insufficiency, autoimmune damage and neurohormonal growth factor deficiency $[3,19]$. The highest resting heart rate resulting from parasympathetic damage is one of the indicators of DAN. However, heart rate may decline with increasing severity of DAN. Fixed heart rate, defined 
as unresponsiveness to moderate exercise, stress or sleep, indicates almost complete cardiac denervation [20]. Changes in autonomic nervous system activity can play an important role in the genesis of cardiac arrhythmias. Hirose et al. [21] showed that atrial vagal denervation facilitates initiation of AF. The study of Gould et al. [22] provides evidence for the presence of heightened atrial sympathetic innervation in patients with persistent AF, suggesting that autonomic remodelling may be part of atrial substrate for $A F$. There are no data concerning effects of DAN on AF.

Twelve years ago, Haissaguerre et al. published a landmark observation describing the causal role of pulmonary veins in the inception of AF [23]. However, the mechanism of impulse initiation in the pulmonary veins has still not been defined. There is more evidence showing that the pulmonary veins are capable of automaticity. Specialized cardiac cells associated with pacemaking, resembling Purkinje cells, have been observed in the pulmonary veins in rats, dogs and humans [24]. The intrinsic component of the autonomic nervous system is composed of a network formed of axons and autonomic ganglia (ganglion plexus) embedded within epicardial fat pads located above both atria and ventricles [25]. One important part of the ganglion plexus has been located in close proximity to the left atrial-pulmonary vein junction. This area is rich in autonomic innervations. Scherlag et al. showed that stimulation of the plexus in this location can convert focal activity in the pulmonary veins into AF [26]. Some research groups have hypothesized that elimination of the ganglion plexus, particularly at the pulmonary vein-atrial junction, could increase the success rate of AF ablation [27]. Also Zimmermann et al. found that in patients with focal ectopy originating from the pulmonary veins, sustained episodes of atrial arrhythmias were mainly dependent on variations of autonomic tone, with a significant shift toward vagal predominance before AF onset [28]. Further studies in this area are needed to elucidate the role of autonomic nervous system dysfunction in pulmonary vein focal activity.

Our study revealed that patients with DAN and paroxysmal AF had statistically significantly longer $\mathrm{P}$-wave duration and dispersion and frequent AF recurrences. According to our knowledge, this is the first published report concerning DAN and P-wave duration and dispersion.

There were some limitations in our study. We assessed a small group of patients and therefore no correlations were made between DAN intensity and P-wave dispersion or duration. Because also other factors such as serum electrolyte level, changes in atrial volume or pressure, etc, might have influenced $\mathrm{P}$-wave duration and dispersion, further studies are needed to determine which other factors may affect $\mathrm{P}$-wave dispersion and duration. Finally, we analysed only ECG-proven episodes of AF; therefore the number of AF episodes seems to be underestimated, especially as PAF episodes were mainly asymptomatic.

In conclusion, the results of our study showed that the occurrence of DAN caused a significant increase in P-wave duration and dispersion, which might be responsible for more frequent development of AF. Therefore, it seems that not DM but diabetic autonomic neuropathy might be a possible risk factor of AF re-initiation.

\section{Acknowledgments}

Funding sources: none. Disclosures: none.

\section{References}

1. Kannel WB, Abbott RD, Savage DD, McNamara PM. Coronary heart disease and atrial fibrillation: the Framingham Study. Am Heart J 1983; 106: 389-96.

2. Kannel WB, Wolf PA, Benjamin EJ, Levy D. Prevalence, incidence, prognosis, and predisposing conditions for atrial fibrillation: population-based estimates. Am J Cardiol 1998; 82: 2N-9N.

3. Vinik Al, Maser RE, Mitchell BD, Freeman R. Diabetic autonomic neuropathy. Diabetes Care 2003; 26: 1553-79.

4. Chen HS, Hwu CM, Kuo BI, et al. Abnormal cardiovascular reflex tests are predictors of mortality in type 2 diabetes mellitus. Diabet Med 2001; 18: 268-73.

5. Dilaveris PE, Gialafos EJ, Sideris SK, et al. Simple electrocardiographic markers for the prediction of paroxysmal idiopathic atrial fibrillation. Am Heart J 1998; 135: 733-8.

6. Dilaveris PE, Gialafos EJ, Andrikopoulos GK, et al. Clinical and electrocardiographic predictors of recurrent atrial fibrillation. Pacing Clin Electrophysiol 2000; 23: 352-8.

7. Yamada T, Fukunami M, Shimonagata T, et al. Dispersion of signal-averaged $P$ wave duration on precordial body surface in patients with paroxysmal atrial fibrillation. Eur Heart J 1999; 20: 211-20.

8. Koide $\mathrm{Y}$, Yotsukura $\mathrm{M}$, Ando $\mathrm{H}$, et al. Usefulness of P-wave dispersion in standard twelve-lead electrocardiography to predict transition from paroxysmal to persistent atrial fibrillation. Am J Cardiol 2008; 102: 573-7.

9. Ewing DJ, Martyn CN, Young RJ, Clarke BF. The value of cardiovascular autonomic function tests: 10 years experience in diabetes. Diabetes Care 1985; 8: 491-8.

10. Coumel P. [Paroxysmal atrial fibrillation: role of autonomic nervous system]. Arch Mal Coeur Vaiss 1994; 87 Spec No 3: 55-62.

11. Coumel P. Paroxysmal atrial fibrillation: a disorder of autonomic tone? Eur Heart J 1994; 15 Suppl A: 9-16.

12. Report and recommendations of the San Antonio conference on diabetic neuropathy. Consensus statement. Diabetes 1988; 37: 1000-4.

13. Gialafos JE. P-wave dispersion. Eur Heart J 1999; 20: 317.

14. Agarwal YK, Aronow WS, Levy JA, Spodick DH. Association of interatrial block with development of atrial fibrillation. Am J Cardiol 2003; 91: 882.

15. Cheema AN, Ahmed MW, Kadish AH, Goldberger JJ. Effects of autonomic stimulation and blockade on signal-averaged P wave duration. J Am Coll Cardiol 1995; 26: 497-502. 
16. Tukek T, Akkaya V, Demirel S, et al. Effect of Valsalva maneuver on surface electrocardiographic P-wave dispersion in paroxysmal atrial fibrillation. Am J Cardiol 2000; 85: 896-9, A10.

17. Imamoglu EY, Oztunc F, Eroglu AG, Onal H, Guzeltas A. Dispersion of the $P$ wave as a test for cardiac autonomic function in diabetic children. Cardiol Young 2008; 18: 581-5.

18. Yazici M, Ozdemir K, Altunkeser BB, et al. The effect of diabetes mellitus on the P-wave dispersion. Circ J 2007; 71: 880-3.

19. Vinik Al. Diagnosis and management of diabetic neuropathy. Clin Geriatr Med 1999; 15: 293-320.

20. Ewing DJ, Clarke BF. Diabetic autonomic neuropathy: present insights and future prospects. Diabetes Care 1986; 9: 648-65.

21. Hirose M, Leatmanoratn Z, Laurita KR, Carlson MD. Partial vagal denervation increases vulnerability to vagally induced atrial fibrillation. J Cardiovasc Electrophysiol 2002; 13:1272-9.

22. Gould PA, Yii M, McLean C, et al. Evidence for increased atrial sympathetic innervation in persistent human atrial fibrillation. Pacing Clin Electrophysiol 2006; 29: 821-9.

23. Haissaguerre M, Jais $P$, Shah DC, et al. Spontaneous initiation of atrial fibrillation by ectopic beats originating in the pulmonary veins. N Engl J Med 1998; 339: 659-66.

24. Wit AL, Boyden PA. Triggered activity and atrial fibrillation. Heart Rhythm 2007; 4 (3 Suppl): S17-23.

25. Armour JA, Murphy DA, Yuan BX, Macdonald S, Hopkins DA. Gross and microscopic anatomy of the human intrinsic cardiac nervous system. Anat Rec 1997; 247: 289-98.

26. Scherlag BJ, Yamanashi W, Patel U, Lazzara R, Jackman WM. Autonomically induced conversion of pulmonary vein focal firing into atrial fibrillation. J Am Coll Cardiol 2005; 45: 1878-86.

27. Pappone C, Santinelli V, Manguso F, et al. Pulmonary vein denervation enhances long-term benefit after circumferential ablation for paroxysmal atrial fibrillation. Circulation 2004; 109: 327-34.

28. Zimmermann M, Kalusche D. Fluctuation in autonomic tone is a major determinant of sustained atrial arrhythmias in patients with focal ectopy originating from the pulmonary veins. J Cardiovasc Electrophysiol 2001; 12: 285-91. 